\title{
AGIMOS COM BASE EM SENTIMENTOS OU RAZÕES? UMA CRÍTICA AO INTELECTUALISMO DE RACHELS
}

We act based on feelings or reasons? A critique of Rachel's intellectualism

Bruno Martinez Portela *

Resumo: O presente artigo tem como objetivo mostrar que nossos sentimentos têm um papel importante nas deliberações morais e que não conseguimos agir com base em razões, como James Rachels supõe. Faremos uma breve análise da teoria moral de Rachels enquanto modelo de teoria intelectualista. Em um segundo momento, apresentaremos as críticas feitas por David Hume às teorias racionalistas modernas visando, em um terceiro momento, mostrar que, se Hume tem razão em suas críticas, Rachels está enganado ao afirmar que devemos agir com base nas melhores razões porque nossas distinções morais dependem de sentimentos de aprovação e desaprovação morais , calcados na natureza humana.

Palavras-chave: Hume. Rachels. Moral. Sentimentos. Razões.

\begin{abstract}
This article aims to show that our feelings have an important role in moral deliberations and we cannot act based on reasons, as James Rachels supposed. First, we will present a brief analysis of moral theory Rachels while the intellectualist theory's model. In a second step, we will show the criticisms made by David Hume to modern rationalistic theories aiming, in a third time, to show that if Hume is right in his criticism, Rachels is wrong in stating that we must act on the best reasons because our distinctions depend on feelings of moral approval and disapproval, rooted in the human nature.
\end{abstract}

Keywords: Hume. Rachels. Moral. Feelings. Reasons.

\footnotetext{
* Doutorando em Filosofia pela Universidade Federal de Santa Maria (UFSM). Email: bmportela@ yahoo.com.br
}

\begin{tabular}{|c|c|c|c|c|c|}
\hline intuitio & $\begin{array}{c}\text { ISSN } \\
1983-4012\end{array}$ & Porto Alegre & Vol.8 $-\mathrm{N}^{\circ} .1$ & $\begin{array}{c}\text { Junho } \\
2015\end{array}$ & p. 75-86 \\
\hline
\end{tabular}




\section{Introdução}

O que nos leva a julgar moralmente uma ação com o boa ou má ? Diferentes tradições filosóficas, sobretudo os filósofos conhecidos como moralistas britânicos dos séculos XVII e XVIII～， tentaram responder essa questão mostrando a diferença entre o papel da razão e da sensibilidade em nossos juízos e ações morais. Os chamados racionalistas morais afirmaram que existem princípios morais independentes dos homens e estes princípios são imutáveis e têm caráter normativo . Cabe à razão, e somente a ela, (1) o papel de descobrir quais ações são moralmente certas e quais são moralmente erradas; e (2) nos motivar a agir conforme o primeiro e evitar o segundo. Os chamados filósofos do senso moral defenderam que nossas distinções morais são provenientes de um senso ou sentimento interno. Nessa medida, nossos juízos não mais tratariam do que é bom ou mau propriamente , mas do que é moralmente louvável ou condenável. David Hume (1711-76) foi simpático a esta última tradição e esforçou-se em mostrar em seu Tratado da Natureza Humana (1739-40) que a razão tem uma função apenas instrumental na moral e não é capaz de cumprir os papéis que os racionalistas a ela conferiram . Nossas distinções morais dependem, segundo ele, de sentimentos de aprovação e desaprovação que são constit utivos da natureza humana e, dessa forma, compartilhados por toda a espécie. Para Hume ${ }^{1}$, cabe à razão apenas descobrir os meios para alcançar os objetos das paixões, justificando sua conhecida frase: "a razão é, e deve ser, apenas a escrava das paixões" ${ }^{2}$.

Com os desdobramentos contemporâneos da discussão moral , novas teorias morais tentaram responder à questão sobre o papel da razão e da sensibilidade sem filiar -se aos filósofos racionalistas ou do senso moral, mas procuraram desenvolver soluções originais que guardam alguma analogia com essas que foram as principais tradições . É o caso da teoria moral de James Rachels (2006) que, embora não possa ser considerado um racionalista semelhante aos modernos, confere um destacado papel à razã o em detrimento da sensibilidade. Em sua obra Elementos de filosofia moral (2006), Rachels ${ }^{3}$, afirma que a moral trata de "consultar a razão" e que "não podemos contar com nossos sentimentos" . Ao analisar os argumentos e soluções de três cas os morais controversos, Rachels ${ }^{4}$ sente-se seguro ao formular uma “concepção mínima da moralidade” que contém ， basicamente, dois princípios , segundo ele , imprescindíveis a qualquer teoria moral, a saber, que a moral é (1) "o esforço em guiar a conduta do

\footnotetext{
${ }^{1}$ HUME. D. Tratado da Natureza Humana. Tradução de Débora Danowski. São Paulo: Editora da UNESP, 2009, p. 450.

${ }^{2}$ HUME. D. Tratado da Natureza Humana. Tradução de Débora Danowski. São Paulo: Editora da UNESP, 2009, p. 451.

${ }^{3}$ RACHELS, J. Os elementos da filosofia moral. Tradução de Roberto Cavallari Filho. São Paulo: Manole, 2006, p. 12.

${ }^{4}$ RACHELS, J. Os elementos da filosofia moral. Tradução de Roberto Cavallari Filho. São Paulo: Manole, 2006, p. 15.
}

\begin{tabular}{|c|c|c|c|c|c|}
\hline intuitio & $\begin{array}{c}\text { ISSN } \\
1983-4012\end{array}$ & Porto Alegre & Vol.8 $-\mathrm{N}^{\circ} .1$ & $\begin{array}{c}\text { Junho } \\
2015\end{array}$ & p. 75-86 \\
\hline
\end{tabular}


indivíduo por meio da razão" e , ao mesmo tempo, (2) que é preciso dar "um peso igual aos interesses de cada indivíduo que será afetado pelo que alguém faça".

Na sequência do presente artigo , pretende-se mostrar que, ao deixar de lado a sensibilidade, Rachels compromete-se com uma teoria que se distancia da experiência da moral da vida comum, ou seja, ao tentar buscar soluções para as questões morais , ele a afasta de seu campo de atuação sem escapar às críticas, acima mencionadas, feitas por Hume ao racionalismo tradicional. O artigo, portanto, será dividido em três seções: na primeira apresentar-se-á a análise de Rachels a uma controvérsia moral particular e o papel que ele confere à razão e ao sentimento na resolução dessa controvérsi a, bem como, partindo disso, o modo pelo qual ele desenvolve sua concepção mínima de moralidade . Na segunda seção, pretende-se expor a crítica humeana ao racionalismo tradicional e como a distinção moral depende de nossos sentimentos de aprovação e desaprovação. Na última seção , pretende-se mostrar como as críticas de Hume, se corretas, inviabilizam a teoria intelectualista de Rachels.

\section{Razão, Imparcialidade e Concepção Mínima de Moralidade: Rachels}

Em sua obra Os elementos da filosofia moral (2006), Rachels afirma ser possível encontrar uma “concepção mínima de moralidade", que sustenta dois princípios que devem nortear qualquer teoria moral O objetivo dessa concepção mínima é garantir que nossos juízos sejam guiados pela razã o sempre considerando os interesses dos indivíduos envolvidos . O autor sugere que a análise de algumas controvérsias particulares pode nos encaminhar a essa concepção mínima . Para os fins deste artigo , é suficiente apresentar a análise feita por de de apenas um destes casos controversos.

\subsection{A busca por argumentos razoáveis}

O primeiro caso é o da bebê Theresa Pearson, nascida na Flórida em 1992 sem partes do encéfalo. Bebês nascidos com a mesma condição de Theresa são chamados anencéfa los, possuindo apenas funções biologicamente automáticas e em geral poucas horas ou dias de vida . A anencefalia pode ser detectada ainda na gravidez e quando isso ocorre é comum , nos Estados Unidos, os pais decidirem por aborto. No caso de Theresa, os pais optaram por não abortar e doar os órgãos da filha. A situação tornou-se complexa, pois os órgãos apenas possuem serventia se retirados antes da morte para evitar a deterioração dos mesmos.

Rachel elenca e analisa os três principais argumento s sendo um favorável e dois desfavoráveis à doação dos órgãos . O favorável é chamado pelo autor de "argumento do benefício" que consiste no seguinte princípio : "se pudermos beneficiar alguém , sem causar danos a ninguém, nós deveríamos

\begin{tabular}{|c|c|c|c|c|c|}
\hline intuitio & $\begin{array}{c}\text { ISSN } \\
1983-4012\end{array}$ & Porto Alegre & Vol.8 $-\mathrm{N}^{\circ} .1$ & $\begin{array}{c}\text { Junho } \\
2015\end{array}$ & p. 75-86 \\
\hline
\end{tabular}


Agimos com base em sentimentos ou razões? Uma crítica ao intelectualismo de Rachels

proceder assim" seria antecipada, todavia, Rachels afirma ser esse caso uma possível exceção, uma vez que a vida pode ser considerada um benefício apenas se nos "habilita a desenvolver atividades, ter pensamentos, ter sentimentos e conviver com outras pessoas (...). Na ausência de tais coisas , a mera existê ncia biológica não tem valor" ${ }^{\prime}$. Segundo a descrição do próprio Rachels , a vida da Theresa não poderia ser cons iderada um benefício, uma vez que ela não desfrutaria de alguns poucos dias a mais . Seria razoável, portanto, aceitar o argumento e doar os órgãos a quem realmente se beneficiaria deles

Os dois argumentos que se opõem à posição acima são o argum ento de que "as pessoas não deveriam ser usadas como meios" e o argumento do "erro de matar" . O primeiro, como o próprio nome sugere, baseia-se no princípio de que "é errado usar pessoas com o meios para os fins de outras"7. O autor explica que, embora essa ideia seja atrativa, ela é vaga. Usamos os outros como meio quando trapaceamos ou coagimos violando sua autonomia, no entanto, a Theresa não pode ser considerada autônoma, logo não haveria trapaça ou coerção nesse caso. Rachels explica que, sempre que uma pessoa não é capaz de tomar decisões, existem duas soluções racionais para decidirmos por ela : ou perguntarmo-nos "o que é melhor pra ela?" ou “o que ela optaria se pudesse nos contar sua preferência?". Rachels ${ }^{8}$ assume que no caso de Theresa "fomos deixados para fazer o que achamos melhor".

O segundo argumento é baseado no princípio : "é errado mata $\mathrm{r}$ uma pessoa para salvar outra"; portanto, se a retirada dos órgãos de Theresa implica sua morte, essa ação incorre necessariamente em um erro. O autor questiona se esse argumento é de fato consistente, uma vez que não é unânime a crença de que matar é sempre injustificado e se esse caso não seria uma exceção ao princípio . Segundo Rachels o bebê está sentenciado à morte e nad a se pode fazer para mudar isso . A retirada de seus órgãos deve ser considerada uma vez que isso poderia salvar outras vidas.

Ao final da análise do caso da bebê Theresa , Rachels afirma que o argumento a favor do transplante dos órgãos de Theresa parece mais forte que os argumentos opostos e sugere que uma solução plausível é ampliar o conceito de morte cerebral aos casos de anencefalia . Como a morte cerebral é utilizada como critério para declarar uma pessoa como morta legalmente , o caso da bebê Theresa seria mais facilmente resolvido.

\footnotetext{
${ }^{5}$ RACHELS, J. Os elementos da filosofia moral. Tradução de Roberto Cavallari Filho. São Paulo: Manole, 2006, p. 03.

${ }^{6}$ RACHELS, J. Os elementos da filosofia moral. Tradução de Roberto Cavallari Filho. São Paulo: Manole, 2006, p. 03.

${ }^{7}$ RACHELS, J. Os elementos da filosofia moral. Tradução de Roberto Cavallari Filho. São Paulo: Manole, 2006, p. 03.

${ }^{8}$ RACHELS, J. Os elementos da filosofia moral. Tradução de Roberto Cavallari Filho. São Paulo: Manole, 2006, p. 04.

${ }^{9}$ RACHELS, J. Os elementos da filosofia moral. Tradução de Roberto Cavallari Filho. São Paulo: Manole, 2006, p. 05.
}

\begin{tabular}{|c|c|l|l|l|l|}
\hline intuitio & $\begin{array}{c}\text { ISSN } \\
1983-4012\end{array}$ & Porto Alegre & Vol.8 $-\mathrm{N}^{\mathrm{o}} .1$ & $\begin{array}{c}\text { Junho } \\
2015\end{array}$ & p. 75-86 \\
\hline
\end{tabular}




\subsection{Razão, imparcialidade e a concepção minima de moralidade}

Rachels busca analisar a coerência interna dos diferentes argumentos . Na controvérsia acima foi possível perceber que o autor evita assumir qualq uer posição durante a análise para melhor confrontar as diferentes perspectivas, destacando que as posições mais razoáveis são preferíveis às opostas . Em sua subseção 1.5 Razão e Imparcialidade, o autor assume que os julgamentos morais devem estar sempre embasados em razões válidas e que é da "natureza da moralidade uma consideração imparcial dos interesses de cada indivíduo" ${ }^{10}$. Afirma ainda que a análise de casos dramáticos como o da bebê Theresa suscitam sentimentos fortes, os quais devem ser desconsiderados para o exercício da reflexão sobre as diferentes posições.

Infelizmente não podemos contar com nossos sentimentos, não importa o quão forte eles possam ser. Nossos sentimentos podem ser irracionais: eles podem ser nada mais do que produtos do preconceito, do egoismo ou da condição cultural. ${ }^{11}$.

O esforço de Rachels em destacar a importância de assegurarmos que melhores razões devem guiar nossos juízos e condutas revela sua preocupação com os diferentes caminhos que nossos sentimentos podem tomar. Nesse sentido, ele alega que casos morais tendem a suscitar sentimentos opostos, e devemos considerar que, nesses casos, apenas uma das posições pode ser a verdadeira.

Se quisermos descobrir a verdade, devemos tentar deixar nossos sentimentos serem guiados o máximo possível pelos argumentos, que podem ser dados pelos pontos de vista opostos. A moralidade é, em primeiro lugar, uma questão de consultar a razão. A coisa certa a fazer moralmente, em qualquer circunstância, é aquela para a qual há as melhores razões ${ }^{12}$.

A razão cumpre uma função privilegiada na teoria moral de Rachels. Ele deixa claro que, quando se trata de moral, devemos "consultar a razão". Certamente o autor está preocupado em assegurar o critério de imparcialidade, algo que os sentimentos supostamente não conseguem garantir. $\mathrm{O}$ título da seção, portanto, antecipa os dois elementos - razão e imparcialidade - fundamentais de sua "concepção mínima da moralidade", a saber:

Moralidade é, minimamente, o esforço em guiar a conduta do indivíduo por meio da razão - ou seja, fazer algo para o qual haja as melhores razões para fazê-lo -

\footnotetext{
${ }^{10}$ RACHELS, J. Os elementos da filosofia moral. Tradução de Roberto Cavallari Filho. São Paulo: Manole, 2006, p. 12.

${ }^{11}$ RACHELS, J. Os elementos da filosofia moral. Tradução de Roberto Cavallari Filho. São Paulo: Manole, 2006, p. 12.

${ }^{12}$ RACHELS, J. Os elementos da filosofia moral. Tradução de Roberto Cavallari Filho. São Paulo: Manole, 2006, p. 12.
}

\begin{tabular}{|c|c|c|c|c|c|}
\hline intuitio & $\begin{array}{c}\text { ISSN } \\
1983-4012\end{array}$ & Porto Alegre & Vol.8 $-\mathrm{N}^{\mathrm{o}} .1$ & $\begin{array}{c}\text { Junho } \\
2015\end{array}$ & p. 75-86 \\
\hline
\end{tabular}



que será afetado pelo que alguém faça ${ }^{13}$.

Na última seção deste artigo voltaremos a essa concepção. Na próxima, pretende-se apresentar a crítica que David Hume fez à tradição racionalista e sua tentativa de fundamentar a moral na pura razão e, nesse sentido, se é possível consultar a razão ou deixar-nos guiar por ela. Ao final da seção, pretende-se expor como, em Hume, a distinção moral entre o louvável ou condenável é dependente de nossa sensibilidade.

\section{David Hume e a Busca por uma Moral Não Racionalista}

Muito filósofos alegaram, ao longo da história, que a razão deve guiar nossos juízos e nossa conduta. Como vimos, esse é o caso de Rachels. Veremos nessa seção que Hume, defensor de uma teoria moral calcada em nossa sensibilidade, elaborou uma tese que se opõe a essa, pois considera que a razão é apenas instrumental e só é capaz de direcionar nossos juízos e ações rumo à satisfação de nossas paixões. Ela sozinha não é capaz de distinguir ações e caracteres moralmente louváveis ou condenáveis, nem nos mover moralmente. Ambas, distinção e motivação moral, segundo Hume, dependem de nossa sensibilidade. $^{14}$

Na presente seção pretende-se apresentar, portanto, o papel da razão e da sensibilidade na moral de Hume com a finalidade de esclarecer sua crítica ao racionalismo e como, a partir disso, ele afirma ser nossas distinções e motivação morais dependentes de sentimentos e não razões. Na última seção, tentarse-á mostrar em que sentido a crítica ao racionalismo inviabiliza a teoria moral intelectualista de Rachels.

\subsection{A razão não motiva}

No segundo livro do Tratado, intitulado "As paixões”, Hume ${ }^{15}$ alega que é lugar comum na filosofia falar sobre o "combate entre paixão e razão" e "dar preferência à razão", cujos preceitos são acatados pelo homem virtuoso. Nessa perspectiva, o agente moral é visto como um ser racional que subjuga todos os princípios ou motivos que não se adequam àqueles preceitos. $\mathrm{O}$ autor afirma que a disputa entre razão e paixão é inexistente e as filosofias que às defendem são falaciosas, uma vez que: "a

\footnotetext{
${ }^{13}$ RACHELS, J. Os elementos da filosofia moral. Tradução de Roberto Cavallari Filho. São Paulo: Manole, 2006, p. 15.

${ }^{14}$ Portanto, são duas questões distintas: a primeira busca descobrir de quem é a função de distinguir moralmente entre o louvável e o condenável (ou certo e errado, para os racionalistas); a segunda versa sobre o que nos leva a agir moralmente, sobre a motivação moral. Uma questão de epistemologia e outra de psicologia moral, respectivamente.

${ }^{15}$ HUME, D. Tratado da Natureza Humana. Tradução de Débora Danowski. São Paulo: Editora da UNESP, 2009, p. 449.
}

\begin{tabular}{|c|c|l|l|l|l|}
\hline intuitio & $\begin{array}{c}\text { ISSN } \\
1983-4012\end{array}$ & Porto Alegre & Vol.8 $-\mathrm{N}^{\circ} .1$ & $\begin{array}{c}\text { Junho } \\
2015\end{array}$ & p. $75-86$ \\
\hline
\end{tabular}


razão sozinha não pode nunca ser motivo para uma ação da vontade" e "nunca poderia se opor à paixão na direção da vontade". ${ }^{16}$

A percepção ${ }^{17}$ de dor e prazer, segundo Hume, foi implantada na mente humana, e é a "principal fonte e princípio motor de todas as suas ações". ${ }^{18}$ As ações dos homens visam buscar o prazer e evitar a dor. A função da razão é descobrir as relações de causa e efeito. Ao descobrir quais objetos são causas de nosso prazer e quais são causas de nossa dor, afirma Hume ${ }^{19}$, somos tomados por uma emoção de propensão ou aversão, respectivamente. Nesse sentido, a razão parece exercer um papel limitado em nossas ações: desejamos determinado objeto anteriormente colocado, e a razão apenas descobre quais os meios para obtê-lo.

Nesse sentido, o entendimento e a volição, segundo o filósofo escocês, são exercidos em âmbitos diferentes. O primeiro no mundo das ideias e o segundo no mundo das realidades. $\mathrm{O}$ entendimento se exerce por demonstração, ou seja, "conforme considere as relações abstratas entre nossas ideias"; ou por probabilidade, ou seja, conforme considere "as relações entre os objetos, que só conhecemos pela experiência"20. A única influência, portanto, que a razão pode ter sobre nossas ações limita-se a sua capacidade de "dirigir nossos juízos sobre causas e efeitos". ${ }^{21}$

Hume está seguro de que o combate entre a razão e as paixões é uma falácia. A moral, segundo ele, depende essencialmente da sensibilidade. A razão possui um papel secundário. Afirmação eternizada em sua passagem: "A razão é, e deve ser, apenas a escrava das paixões, e não pode aspirar a outra função além de servir e obedecer a elas" 22 .

\footnotetext{
${ }^{16}$ A vontade, para Hume, é a "impressão interna que sentimos e de que temos consciência quando deliberadamente geramos um novo movimento em nosso corpo ou uma nova percepção em nossa mente". HUME, D. Tratado da Natureza Humana. Tradução de Débora Danowski. São Paulo: Editora da UNESP, 2009. p. 435.

${ }^{17}$ Para Hume, qualquer ação da mente, incluindo juízos morais, são percepções. E as percepções, por sua vez, se reduzem a impressões e ideias. Hume (2009) afirma que as impressões e as ideias se distinguem por sua força e vividez. As impressões são as percepções mais fortes, como as sensações, afetos e sentimentos. As ideias, por sua vez, são as percepções mais fracas, ou cópias das impressões gravadas na memória e na imaginação.

${ }^{18}$ A natureza implantou na mente humana uma percepção do bem e do mal, ou, em outras palavras, da dor e do prazer, que é a principal fonte e princípio motor de todas as suas ações. HUME, D. Tratado da Natureza Humana. Tradução de Débora Danowski. São Paulo: Editora da UNESP, 2009, p. 149.

${ }^{19}$ HUME, D. Tratado da Natureza Humana. Tradução de Débora Danowski. São Paulo: Editora da UNESP, 2009, p. 448.

${ }^{20}$ HUME, D. Tratado da Natureza Humana. Tradução de Débora Danowski. São Paulo: Editora da UNESP, 2009, p. 449.

${ }^{21}$ É a perspectiva de dor ou prazer que gera aversão ou propensão ao objeto; e essas emoções se estendem àquilo que a razão e a experiência nos apontam como causas e os efeitos desse objeto. Nunca teríamos o menor interesse em saber que tais objetos são causas e tais outros são efeitos, se tanto as causas como os efeitos nos fossem indiferentes. Quando os próprios objetos não nos afetam, sua conexão jamais pode lhes dar uma influência; e é claro que, como a razão não é senão a descoberta dessa conexão, não pode ser por meio dela que os objetos são capazes de nos afetar. HUME, D. Tratado da Natureza Humana. Tradução de Débora Danowski. São Paulo: Editora da UNESP, 2009, p. 450.

${ }^{22}$ HUME, D. Tratado da Natureza Humana. Tradução de Débora Danowski. São Paulo: Editora da UNESP, 2009, p. 451.
}

\begin{tabular}{|c|c|l|l|l|l|}
\hline intuitio & $\begin{array}{c}\text { ISSN } \\
1983-4012\end{array}$ & Porto Alegre & Vol.8 $-\mathrm{N}^{\circ} .1$ & $\begin{array}{c}\text { Junho } \\
2015\end{array}$ & p. $75-86$ \\
\hline
\end{tabular}


Para sustentar que não há oposição entre razão e paixões, Hume ${ }^{23}$ afirma que "uma paixão é uma existência original” e não uma cópia de outra existência. Dessa forma, quando temos raiva, estamos realmente "possuídos por essa paixão". Segue-se disso que "é impossível haver uma oposição ou contradição entre essa paixão e a verdade ou a razão; pois tal contradição consiste na discordância entre certas idéias, consideradas como cópias, e os objetos que elas representam."24.

Na próxima seção, veremos como a moral, para Hume, depende de sentimentos de aprovação e desaprovação morais.

\subsection{A moral depende de um "sentido moral"}

Podemos agora resumir o argumento de Hume sobre a impossibilidade de a razão realizar distinções morais da seguinte forma: (1) Nossas distinções morais (crenças morais) nos motivam; (2) a razão não nos motiva; (3) Logo, a razão não pode ser o fundamento de nossas distinções morais. Em suas palavras: "A moral desperta paixões, e produz ou impede ações. A razão, por si só, é inteiramente impotente quanto a esse aspecto. As regras da moral, portanto, não são conclusões de nossa razão." 25 .

Hume desafia o racionalista a mostrar quais são os elementos factuais que tornam uma ação imoral, apenas assim poder-se-ia refutar o argumento acima. Para o autor, a moral racionalista pressupõe que uma ação, para ser boa, deve adequar-se a certas relações, eternas e imutáveis, que independem de nosso gosto e experiência. Mas para isso a razão teria de ser capaz de descobrir essas relações e nos motivar a agir em função delas. ${ }^{26}$ Se a moral diz respeito a essas relações, ela deve influenciar nossos juízos em qualquer situação onde as encontremos. ${ }^{27}$ No entanto, Hume afirma que somos incapazes de encontrar o fato moral das ações.

O vício escapa-nos por completo, enquanto consideramos o objeto. Não o encontraremos até dirigirmos nossa reflexão para nosso próprio íntimo e darmos

\footnotetext{
${ }^{23}$ HUME, D. Tratado da Natureza Humana. Tradução de Débora Danowski. São Paulo: Editora da UNESP, 2009, p. 451.

${ }^{24}$ HUME, D. Tratado da Natureza Humana. Tradução de Débora Danowski. São Paulo: Editora da UNESP, 2009, p. 451.

${ }^{25}$ HUME, D. Tratado da Natureza Humana. Tradução de Débora Danowski. São Paulo: Editora da UNESP, 2009, p. 497.

${ }^{26}$ Se o pensamento e o entendimento sozinhos fossem capazes de fixar os limites do certo e do errado, a qualidade de virtuoso e vicioso teria de estar em algumas relações de objetos, ou então ser uma questão de fato, descoberta por nosso raciocínio. HUME, D. Tratado da Natureza Humana. Tradução de Débora Danowski. São Paulo: Editora da UNESP, 2009, p. 501-502.

${ }^{27}$ Segundo Hume se as mesmas relações não possuem as mesmas características, elas não devem ser descobertas apenas pela razão. O exemplo que, segundo o autor, refuta o racionalista é o do "parricídio", universalmente considerado imoral, comparado com uma semente de carvalho que cresce gradativamente e destrói o carvalho que a gerou. As relações, segundo o autor, são as mesmas, o ser gerado mata quem o gerou. Se considerarmos imoral o exemplo do homem, mas não o do carvalho, a moral não pode tratar-se de relações e, por consequência, a razão não pode ser a fonte da distinção moral.
}

\begin{tabular}{|c|c|c|c|c|c|}
\hline intuitio & $\begin{array}{c}\text { ISSN } \\
1983-4012\end{array}$ & Porto Alegre & Vol.8 $-\mathrm{N}^{\mathrm{o} .1}$ & $\begin{array}{c}\text { Junho } \\
2015\end{array}$ & p. $75-86$ \\
\hline
\end{tabular}


com um sentimento de desaprovação, que se forma em nós contra essa ação. Aqui há um fato, mas ele é objeto de sentimento [feeling], não da razão ${ }^{28}$.

As ações são consideradas, portanto, louváveis ou condenáveis porque sua apreciação nos desperta sentimentos de aprovação ou reprovação. Hume ${ }^{29}$ afirma que as ações mesmas não possuem moralidade. "É preciso um motivo virtuoso para que uma ação se torne virtuosa", e as consideramos em nossos juízos porque elas são signos de nossos motivos. O mérito está relacionado a princípios duradouros da mente e do caráter.

Algumas ações, afirma Hume ${ }^{30}$, nos causam um sentimento peculiar de prazer ou dor. O primeiro indica a virtude e gera "orgulho ou amor", e o segundo indica o vício e gera "humildade ou ódio". Dessa forma, mesmo uma ação que é geralmente condenável é perdoada se realizada por alguém que não tem motivações ruins. ${ }^{31}$ A melhor ação, portanto, é a ação feita com bons motivos, ou seja, é aquela ação que uma pessoa virtuosa faria. ${ }^{32}$ Ao analisar as características ou qualidades pessoais que são consideradas virtuosas, Hume descobriu que as ações e caracteres úteis ou agradáveis são objetos de nosso louvor. Nesse sentido, preferimos uma ação útil ou agradável porque levamos em consideração o interesse dos indivíduos por ela afetados. ${ }^{33}$

A utilidade é apenas uma tendência à obtenção de um certo fim. (...) Assim, se a utilidade é uma fonte do sentimento moral, e se essa utilidade não é invariavelmente considerada apenas em referência ao próprio sujeito, segue-se que tudo o que contribui para a felicidade da sociedade recomenda-se diretamente à nossa aprovação e afeto. Eis aqui um princípio que explica em grande medida a origem da moralidade ${ }^{34}$.

\footnotetext{
${ }^{28}$ HUME, D. Tratado da Natureza Humana. Tradução de Débora Danowski. São Paulo: Editora da UNESP, 2009, p. 508.

${ }^{29}$ HUME, D. Tratado da Natureza Humana. Tradução de Débora Danowski. São Paulo: Editora da UNESP, 2009, p. 518.

${ }^{30}$ HUME, D. Tratado da Natureza Humana. Tradução de Débora Danowski. São Paulo: Editora da UNESP, 2009, p. 614.

${ }^{31}$ Hume (2009, p. 448) chega a mencionar que o arrependimento pode redimir uma pessoa de todos os seus crimes, "sobretudo se acompanhado de uma evidente reforma na vida e nos hábitos".

32 "A questão inicial de Hume, como a de Hutcheson, não diz respeito aos espectadores ou aos agentes, mas à presença da moralidade em um universo newtoniano de corpos em movimento. Dadas as suposições naturalistas de Hume sobre o que podemos observar, a questão é: Como alguns corpos são movidos por pensamentos e expressões morais? A resposta confirma a negação de Hume de que há algo especial na ação. Todos os fatos sobre a moral podem ser explicados sem invocá-la". SCHNEEWIND, J. B. A invenção da autonomia: uma história da filosofia moral Moderna. São Leopoldo: Unisinos, 2001. 667 p. (Coleção Idéias, 2). Tradução: Magda França Lopes, p. 396

${ }^{33}$ HUME, D. Uma Investigação sobre os princípios da moral. Tradução de José Oscar de Almeida Marques. Campinas: Editora da UNICAMP, 1995, p. 83. Levamos em conta o interesse dos outros por simpatia, que é um mecanismo através do qual nossos sentimentos se comunicam como "cordas afinadas no mesmo tom, em que o movimento de uma se comunica às outras, todos os afetos passam prontamente de uma pessoa a outra, produzindo movimentos correspondentes em todas as criaturas" HUME, D. Tratado da Natureza Humana. Tradução de Débora Danowski. São Paulo: Editora da UNESP, 2009, p. 615.

${ }^{34}$ HUME, D.. Uma Investigação sobre os princípios da moral. Tradução de José Oscar de Almeida Marques. Campinas: Editora da UNICAMP, 1995, p. 84.
}

\begin{tabular}{|c|c|c|c|c|c|}
\hline intuitio & $\begin{array}{c}\text { ISSN } \\
1983-4012\end{array}$ & Porto Alegre & Vol.8 $-\mathrm{N}^{\mathrm{o} .1}$ & $\begin{array}{c}\text { Junho } \\
2015\end{array}$ & p. 75-86 \\
\hline
\end{tabular}


Na próxima seção, pretende-se mostrar que a teoria de Rachels é incapaz de se sustentar frente às críticas de Hume. A moralidade não pode excluir nossos sentimentos. Eles possuem um papel muito importante na deliberação e motivação morais.

\section{A moral depende de sentimentos e não razões}

Um dos métodos mais comuns para se justificar uma ou outra teoria moral é utilizar hipóteses para esclarecer quais as ações são corretas ou não em dada situação. Às vezes, porém, as hipóteses são tendenciosas e não se remetem ao agir comum. O cenário é montado para demonstrar como se deve operar segundo a teoria em questão. O indivíduo que deve decidir qual via de ação tomar é deslocado totalmente de sua vida e de toda a complexidade que ela comporta, de modo a ser visto à parte de seus gostos pessoais, família, desejos e aspirações. O agente moral, nesses casos, se assemelha a um robô insensível que deve calcular e agir com base em princípios puramente racionais. A justificativa que geralmente se assume para esse tipo de abordagem é tornar a análise mais imparcial garantindo a universalidade e, consequentemente, valores não relativos na teoria moral. É curioso, porém, que, ao defender certos princípios, alguns filósofos tornem a moral um estudo abstrato e por vezes sem utilidade para a nossa vida.

Nesse sentido, quando Rachels exclui os sentimentos da vida moral e afirma que devemos "agir com base em boas razões" e "considerar igualmente os interesses de cada indivíduo", ele tira o elemento que humaniza o agente moral. Mas, se Hume estava correto ao afirmar que a razão é instrumental e não prática, não somos capazes de "agir com base em razões", pois o fim da ação nunca é racional, ela é sensível.

Quando Rachels assume que os sentimentos não devem estar envolvidos nas nossas deliberações morais, ele deveria ter se referido apenas àqueles sentimentos gerados pelos nossos preconceitos e que de alguma forma dão suporte a falsas crenças. Ele poderia ter afirmado que nossos juízos deveriam estar totalmente livre dessa espécie de sentimentos, pois isso garantiria a imparcialidade exigida pela moralidade. Mas não foi essa, como vimos, a sua formulação. Segundo Rachels, sentimentos podem ser nada mais que frutos de preconceito ou egoísmo e nos levar a conclusões enganosas. O que Rachels não reconheceu é que não se segue disso que todos os sentimentos são negativos ou descartáveis. Existe um salto inválido da premissa "alguns sentimentos não podem mesclar-se a raciocínios morais" para a conclusão "nenhum sentimento deve mesclar-se a raciocínios morais". Esse erro compromete, como veremos na próxima seção, sua teoria moral.

É difícil pensar em uma consideração igual de interesses sem que a razão ou reflexão tenham algum papel a desempenhar. Afinal, nossos sentimentos em geral não são imparciais. Contudo, é ainda

\begin{tabular}{|c|c|c|c|c|c|}
\hline intuitio & $\begin{array}{c}\text { ISSN } \\
1983-4012\end{array}$ & Porto Alegre & Vol.8 $-\mathrm{N}^{\circ} .1$ & $\begin{array}{c}\text { Junho } \\
2015\end{array}$ & p. 75-86 \\
\hline
\end{tabular}


mais difícil pensar que consideramos os interesses dos outros sem que tenhamos alguma inclinação ou sentimento na base dessa consideração.

Hume, como visto, afirmou que não existe uma real oposição entre as paixões e a razão. Sendo as paixões existências originais e não cópias da existência, elas mesmas não possuem valor de verdade. Sendo assim, "não é contrário à razão eu preferir a destruição do mundo inteiro a um arranhão em meu dedo" ${ }^{135}$. Portanto, se consideramos os interesses dos outros em nossas deliberações e ações morais, não é por causa da razão, mas porque possuímos alguma inclinação ao bem da humanidade ou alguma espécie de sentimento ou inclinação que nos faça assim considerar.

A humanidade como um todo assemelha-se tanto ao princípio do Bem que, quando nossas disposições não estão corrompidas pelo interesse, o ressentimento ou a inveja, estamos sempre inclinados, pela nossa filantropia natural, a dar preferência à felicidade da sociedade e, conseqüentemente, à virtude, mais do que a seu oposto ${ }^{36}$.

Mas fica a pergunta: como é possível conciliar nossos sentimentos egoístas com uma consideração imparcial dos interesses dos outros? ${ }^{37}$ A resposta a essa questão demandaria outro artigo. Mas pode-se apontar um dos caminhos: em Hume, para dar um exemplo, a resposta a esta questão está atrelada ao modo como o mecanismo da simpatia ocorre. Nossos juízos dependem de uma capacidade de nos colocarmos na posição de alguém, portanto, nossas preferências e interesses de natureza pessoal são deixados momentaneamente de lado.

Quando julgamos um caráter, o único interesse ou prazer que parece o mesmo para todo espectador é o da própria pessoa cujo caráter está sendo examinado, ou o daqueles que têm alguma conexão com ela. E embora esses interesses e prazeres nos afetem de maneira mais fraca que os nossos, são mais constantes e universais, e por isso contrabalançam estes últimos até mesmo na prática, além de serem os únicos admitidos na especulação como critérios de virtude e moralidade. Apenas eles produzem essa sensação ou sentimento particular de que dependem as distinções morais ${ }^{38}$.

\footnotetext{
${ }^{35}$ HUME, D. Tratado da Natureza Humana. Tradução de Débora Danowski. São Paulo: Editora da UNESP, 2009, p. 452.

${ }^{36}$ HUME, D.. Uma Investigação sobre os princípios da moral. Tradução de José Oscar de Almeida Marques. Campinas: Editora da UNICAMP, 1995, p. 648.

${ }^{37}$ Outra crítica, que não vamos explorar neste artigo, diz respeito à incapacidade de uma teoria intelectualista compreender e ajuizar de maneira correta uma decisão moral baseada em vivências e projeções de cunho sentimental. No caso da teoria humeana, se estamos a par das inclinações, sentimentos, projeções de uma pessoa bem como o contexto em que ela se encontra, somos capazes de compreender o que levou ela a fazer essa ou aquela escolha e julgar adequadamente suas ações a partir de seus motivos.

${ }^{38}$ HUME, D. Tratado da Natureza Humana. Tradução de Débora Danowski. São Paulo: Editora da UNESP, 2009, p. 631.
}

\begin{tabular}{|c|c|c|c|c|c|}
\hline intuitio & $\begin{array}{c}\text { ISSN } \\
1983-4012\end{array}$ & Porto Alegre & Vol.8 $-\mathrm{N}^{\circ} .1$ & $\begin{array}{c}\text { Junho } \\
2015\end{array}$ & p. 75-86 \\
\hline
\end{tabular}




\section{Considerações Finais}

O presente artigo teve como pretensão mostrar que não é possível, como sugeriu Rachels, agir com base em razões. Nossos juízos e ações morais são dependentes, como nos mostrou Hume, de nossa sensibilidade. Ao apresentar a concepção mínima da moral de Rachels, percebe-se sua tentativa em atribuir à razão um papel destacado e esforço de deixar de lado nossos sentimentos nas deliberações morais, pois tais sentimentos podem ser egoístas ou estar carregados de preconceitos. Todavia, as críticas de David Hume ao racionalismo moderno, apresentadas na segunda seção, poderiam ser atribuídas também à teoria de Rachels.

Portanto, o modelo intelectualista apresentado por Rachels, principalmente os pressupostos de sua concepção mínima de moral - que buscavam garantir que nossos argumentos fossem conduzidos por boas razões, sem deixar de considerar os interesses dos indivíduos envolvidos - não poderiam sustentar-se frente às críticas de Hume. Primeiramente porque não somos capazes de agir com base em razões. E, em segundo lugar, porque a consideração que temos ou poderíamos ter pelos interesses dos outros não pode ser de origem racional. Tanto as ações como a consideração dos interesses dos outros dependem, como visto, de nossa sensibilidade.

Embora seja possível apontar algumas dificuldades no presente artigo - como a distância temporal entre os autores, o imenso material sobre diferentes interpretações dos autores e temas aqui trabalhados ele deve ser considerado como um modesto esforço para mostrar que uma boa teoria moral não deve ignorar elementos essenciais da experiência moral cotidiana: nossos sentimentos.

\section{Referências}

HUME, D. Tratado da Natureza Humana. Tradução de Débora Danowski. São Paulo: Editora da UNESP, 2009. . Uma Investigação sobre os princípios da moral. Tradução de José Oscar de Almeida Marques. Campinas: Editora da UNICAMP, 1995.

RACHELS, J. Os elementos da filosofia moral. Tradução de Roberto Cavallari Filho. São Paulo: Manole, 2006. SCHNEEWIND, J. B. A invenção da autonomia: uma história da filosofia moral Moderna. São Leopoldo: Unisinos, 2001. 667 p. (Coleção Idéias, 2). Tradução: Magda França Lopes.

Recebido em: 26/08/2014

Aprovado para publicação em: 23/05/2015

\begin{tabular}{|c|c|c|c|c|c|}
\hline intuitio & $\begin{array}{c}\text { ISSN } \\
1983-4012\end{array}$ & Porto Alegre & Vol.8 $-\mathrm{N}^{\circ} .1$ & $\begin{array}{c}\text { Junho } \\
2015\end{array}$ & p. 75-86 \\
\hline
\end{tabular}

